\title{
Analysis of the causes of maternal death in eclampsia
}

\author{
Aparna Khan ${ }^{1}$, Arindam Ghosh ${ }^{2}$, Pradip Kumar Banerjee ${ }^{3}$, \\ Tapan Kumar Mondal ${ }^{4}$ \\ 1. Associate Professor, 2. Junior Resident, 3,4. Professor \\ ${ }^{1,2,3,4}$ Department of Obstetrics \& Gynecology, Burdwan Medical College, West Bengal, India
}

\begin{abstract}
Objective: To analyze the causes of maternal death in eclamptic mothers. Materials and method: The study was conducted over a period of one year 1.1.2012-31.12.2012 in all eclamptic mothers. Pregnancy was terminated in all antenatal eclampsia irrespective of gestational age. All of them were treated with Pritchard regimen of Magnesium Sulphate $\left(\mathrm{MgSO}_{4}\right)$. Preeclampsia profile and special investigations were done. Sublingual/ intranasal/oral nifedipine and oral labetalol were used as antihypertensive. Results: Incidence of eclampsia was $3.57 \%$, case fatality rate was $3.57 \%$ and maternal mortality ratio was $4.32 / 1000$ live births. $29.76 \%$ maternal death was due to eclampsia. All 25 dead mothers were hypertensive during admission. Among them 64\% (16) mothers had severe hypertension. $44 \%$ mothers had repeated convulsion. In majority (60\%) $\mathrm{MgSO}_{4}$ regimen could be started after $12 \mathrm{hrs}$ convulsion. $33.33 \%$ of dead mothers delivered within $12 \mathrm{hr}$ of admission. $9(42.85 \%)$ mothers died before delivery. 3 mothers came after outside delivery. $36 \%$ mothers died within 12hrs. $48 \%$ mothers died in the next 12 hrs and 16\% (4) mothers died 48hrs after admission. 52.38\% mothers had vaginal delivery. Only $4.7 \%$ had caesarean delivery. $40 \%$ mothers died of cerebral hemorrhage. $28 \%$ mothers died of pulmonary edema, 12\% due to postpartum hemorrhage and 2 mothers due to hepatic coma. One mother died of aspiration, one mother due to septicemia. One died due to acute renal failure. Conclusion: we have a long way to go to achieve the goal to reduce the maternal mortalily due to preventable causes. We have to improve our existing health care delivery system, referral system and infrastructure before achieving the target.
\end{abstract}

Key words: eclampsia, mothers,

\section{Introduction}

Eclampsia is a life threatening emergency and leading cause of maternal death in India even today. Eclampsia precedes preeclampsia in $80 \%$ cases although it is hard to predict which women with preeclampsia go on to have eclampsia. Once eclampsia started the prognosis of mother and baby becomes gloomy. Various complicating causes are responsible for maternal death in eclampsia. The present study was undertaken to analyze the causes of maternal death in eclampsia mothers.

\section{Materials And Method}

The study was conducted over a period of one year ( $1^{\text {st }}$ January to $31^{\text {st }}$ December 2012) in all eclamptic mothers. The questionnaire regarding age, parity, socio-economic condition, antenatal supervision, time of onset of convulsions, number of convulsions before admission were asked to the accompanying relatives after admission. The mothers were thoroughly evaluated to note down the mental status, higher function, vitals and evidence of any complication. Preeclampsia profile such as urine for protein, complete hemogram including platelets count, liver function tests, renal function tests, coagulation profile (bed side clotting test was done during IV canulation) were sent at the convenient time. CT scan was done in those unconscious mothers whose blood investigations excluded other complicating cause of eclampsia. Pregnancy was terminated in all antenatal eclampsia irrespective of gestational age. All of them were treated with Pritchard regimen of $\mathrm{MgSO}_{4}$ which was started within $10 \mathrm{~min}$ of admission although loading dose of $\mathrm{MgSO}_{4}$ for active convulsion was given immediately. For one mother $\mathrm{MgSO}_{4}$ was withheld as urine output was nil since admission. Hypertension was controlled with sublingual/ intranasal/oral nifedipine and oral labetalol. Hypertensive crisis was managed mostly with sublingual or intranasal nifedipine and sometimes with intravenous (IV) labetalol (because of cost factor hypertensive crisis was managed mostly with sublingual/ intranasal nifedipine instead of IV labetalol). Any convulsion after $\mathrm{MgSO}_{4}$, admission-delivery, admission-death, neonatal outcome and cause of death were noted.

\section{Results}

Total 700 eclamptic mothers were admitted. Among them 25 mothers were died. Total delivery was 19580 , live birth was 19460 and total maternal death was 84 . So the incidence of eclampsia was $3.57 \%$, case fatality rate was $3.57 \%$ and maternal mortality ratio was $4.32 / 1000$ live births. $29.76 \%$ death was due to eclampsia. $21(84 \%)$ death occurred in antepartum and $4(16 \%)$ in postpartum eclampsia mothers. All dead 
mother were antenatally unsupervised and all of them belonged to poor family. A large number of mothers belonged to undeveloped poor tribal family. Because of lack of education and awareness they did not even go for antenatal checkup. $84 \%$ of mothers belonged to $<25 \mathrm{yr}$ age among them $36 \%$ mothers were teen aged and $48 \%$ belonged to $20-24 y r$ age group. $16 \%$ mothers had age $\geq 25$ yr. Female child is a burden for the poorer class. Mostly they are illiterate and married off early. This is not only due to economic condition but also because of lack of education and awareness. Due to prevailing customs it is difficult for them to get married as the age advances. All 25 dead mothers were hypertensive during admission. Among them 64\% (16) mothers had severe hypertension whereas $32 \%$ (8) had mild hypertension on admission. One patient came in shock which she developed following childbirth at a local nursing home from which she could not be recovered. Maximum blood pressure that we observed in our study was $240 / 130 \mathrm{~mm}$ of $\mathrm{Hg} .44 \%$ of the dead mothers had repeated convulsion. For the majority $(60 \%) \mathrm{MgSO}_{4}$ regimen could be started $12 \mathrm{hrs}$ after convulsion. Most of the mothers first went to nearest heath centres which in turn referred the mothers to the tertiary care hospital. The distance of the referring hospitals varies from 10-50 KM. However transport and economical factors were also responsible for delayed admission. 33.33\% mothers delivered within $12 \mathrm{hrs}$ and $9.52 \%$ of them delivered $12 \mathrm{hrs}$ after admission. 9 (42.85\%) mothers died before delivery. Most of them have some complications at the time of admission. There was no intensive care unit for the monitoring of eclampsia mothers. So caesarian section could not be done despite having poor bishop score and remote possibility of vaginal delivery. $14.28 \%$ ante-partum eclampsia admitted after delivery. 52.38\% mothers had vaginal delivery. $4.7 \%$ had caesarean delivery. $66.66 \%$ babies were stillborn and $47.61 \%$ of the babies were live. $36 \%$ mothers died within $12 \mathrm{hrs} .48 \%$ mothers died in the next 12 hrs and another 16\% (4) mothers died 48hrs after admission i.e. 3days, 4days, 5days and 7days after admission.

Table 2 analyses cause of death in eclampsia mothers. Most common cause of death in our study was cerebral hemorrhage. $40 \%$ mothers died of cerebral hemorrhage. Death due to pulmonary edema was also quite high. 28\% mothers died of pulmonary edema. Postpartum hemorrhage was responsible for $12 \%$ mothers. One mother died of traumatic PPH following forceps delivery. Hepatic coma was the cause of death for $2(8 \%)$ mothers. Death of one mother was due to aspiration, whereas one mother died of septicemia. One mother died due acute renal failure.

\section{Discussion}

In this research the incidence of eclampsia was $3.57 \%$ Which is similar to study done at neighbouring state. ${ }^{1}$ In Kerala it is 3.8\%, 4.9\% in Andra Pradesh, 15\% in Madhya Pradesh and $20.7 \%$ in Bihar ${ }^{2}$. These figures are not only higher in compare to other developing countries with the incidence of 1 in 100 to 1 in1700 pregnancies $^{3,4,5}$ but also in other part of India as in Karnataka. ${ }^{6,7,8}$ However the incidence is higher in neighboring country Dhaka where it is $9 \%{ }^{9}$ The incidence of eclampsia in developed countries is much lower with the incidence 1 in 3250 pregnancies in $\mathrm{US}^{10}$ and 1 in 2000 pregnancy in Europe. ${ }^{11}$ In developed countries, the incidence of eclampsia is significantly low probably because of uniform national health care policy and comprehensive antenatal care with early detection of pre eclampsia, and its management. Case fatality rate in the study was $3.57 \%$ which is similar to study of Singh et $\mathrm{al}^{1}$ and Suita et $\mathrm{al}^{7}$ and maternal mortality ratio was 4.32/1000 live births. Eclampsia contributed $29.76 \%$ of maternal death which is similar to study of Arora et al ${ }^{12}$ but higher than Sunita et $\mathrm{al}^{7}$, Singh et al. ${ }^{1}$

$44 \%$ mothers had repeated convulsion. $60 \%$ mothers received treatment $>12 \mathrm{hrs}$ after convulsion. $33.33 \%$ mothers delivered within $12 \mathrm{hrs}$ of admission although not within $12 \mathrm{hrs}$ of onset of convulsion. $9.52 \%$ delivered $12 \mathrm{hrs}$ after admission. Bhalero A. reported adverse maternal and prenatal outcome associated increased interval between onset of convulsion and delivery interval. ${ }^{13} 42.85 \%$ mothers died before delivery. Once a complication had already developed, magnesium sulphate could not prevent the sequel of complications. ${ }^{9}$

$52.38 \%$ mothers had vaginal delivery. $4.7 \%$ had caesarean delivery. Other Indian studies showed vaginal delivery was the most common mode of delivery followed by caesarean section. ${ }^{1,6}$ The preferred mode of delivery in Western studies is CS even if estimated fetal weight is low, while the Indian trend continues to be more towards vaginal delivery, thus affecting the prenatal outcome. ${ }^{14} 64 \%$ mothers died $12 \mathrm{hrs}$ after admission and start of therapy. Once complication started $\mathrm{MgSO}_{4}$ could not halt the consequences.

$40 \%$ mothers died of cerebral hemorrhage. Hepatic coma was the cause of death for $2(8 \%)$ mothers. In Africa $45.5 \%$ of hypertensive maternal death was due to cerebral complications. ${ }^{15}$ Intracranial hemorrhage remains the commonest final cause of death in Hypertensive Disorder of Pregnancy in Africa. Although the exact mechanisms that cause hypertension and intracranial hemorrhage are not clearly understood, it appears that systolic and diastolic hypertension play a role. It is generally accepted that diastolic blood pressures of $\geq 110$ $\mathrm{mmHg}$ are linked with intracranial pathology, but recently systolic hypertension has also been found to play a significant role. A systolic blood pressure value above which urgent antihypertensive treatment should be given has been identified as 155 - 160 mmHg. ${ }^{16}$ The latest Why Women Die publication (2003 - 2005) recommends 
that 'women with a systolic blood pressure of $>160 \mathrm{mmHg}$ need antihypertensive treatment. Consideration should also be given to initiating antihypertensive treatment at lower blood pressure values if the overall clinical picture suggests rapid deterioration with anticipation of severe hypertension. ${ }^{17}$

In our study $28 \%$ mothers died of pulmonary edema. In the latest UK report (Why Women Die) there were no deaths from pulmonary causes alone, an improvement probably due to the availability of good fluid management clinical protocols. Only 3 out of 25 dead mothers died of PPH. Fortunately death due to PPH has greatly been decreased because of implementation of Emergency Obstetric Care with mandatory active management of third stage of labor and prompt management of $\mathrm{PPH}$.

\section{Conclusion}

we have a long way to go to achieve the goal to reduce the maternal mortalily due preventable causes. We have to improve our existing health care delivery system, referral system and infrastructure before achieving the target.

\section{References}

[1] Singh S, Behera A. Eclampsia in Eastern India: Incidence, Demographic Profile And Response To Three Different Anticonvulsant Regimes Of Magnesium Sulphate. The Internet J Gynecol Obstet 2010; 15(2):

[2] Sontakke P, Reshmi RS, Sebastian D. Obstetric morbidity among currently married women in selected states of India. J Fam Welf. 2009; 55: 17-26.

[3] World Health Organisation International. Collaborative Study of Hypertensive Disorders of pregnancy. Geographic variation in the incidence of hypertension in pregnancy. Am J Obstet Gynecol 1958: 158: 80-83.

[4] Crowther CA. Eclampsia at Harare Maternity Hospital - An epidemiological study. S Afr Med J 1985; 68: 927-929

[5] Bergstom S. Povey G, Songane F, Ching C. Seasonal incidence of eclampsia and its relationship to meteorological data in Mozambique: J Perinat Med 1992; 20: 153-158

[6] Pradeep M. R. Lalitha Shivanna. Retrospective Study of Eclampsia in a Teaching Hospital. Int J Recent Trends in Science And Technology 2013; Volume 8(3):171-173.

[7] Sunita T.H., Rathnamala M .Desai. Eclampsia in a Teaching Hospital: Incidence, clinical profile and response to Magnesium Sulphate by Zuspan's regimen. IOSR Journal of Dental and Medical Sciences (IOSR-JDMS) 2013; Volume 4(2): 01-05.

[8] Rajasri G. Yaliwal P.B. Juju, M. Vanishee. Eclampsia and Perinatal Outcome A Retrospective Study in a Teaching Hospital. Journal of Clinical and Diagnostic Research. 2011 October, Vol-5(5): 1056-1059.

[9] Begum MR, Begum A, Quadir E, Akter S, Shamsuddin L. Eclampsia: Still a problem in Bangladesh. Med Gen Med 2004;6: 52

[10] Ventura SJ, Martin JA, Curtin SC et al. Births: Final date for 1998. National Vital Statistics Reports, Vol. 48, No. 3, Hyattsville, Md, National Center for Health Statistics 2000.

[11] Douglas KA, Redman CWG. Eclampsia in the United Kingdom. BMJ 1994; 309:1395-1400.

[12] Arora R, Ganguli R.P., Swain S, Oumachigui A, Rajaram P. Determinants of Maternal Mortality in Eclampsia in India. Australian and New Zealand Journal of Obstetrics and Gynaecology 1994; 34(5): 537-539.

[13] Balerao A, Kulkarni S, Ghike S, Kawthalkar A, Joshi S, Somalwar S. Eclampsia: Maternal and Fetal Outcome. JSAFOG2013;5(1):19-21.

[14] Bathla S, Suneja A, Guleria K, Agrawal N. Dilatin as anticonvulsant in eclampsia. J Indian Med Assoc 2002;100:561-564

[15] National Committee on Confidential Enquiries into Maternal Deaths. Saving Mothers Fourth Report 2005-2007. Pretoria: Department of Health, 2009.

[16] Martin Jr NL, Thigpen MF, Moore RC, et al. Stroke and pre-eclampsia and eclampsia: a paradigm shift focussing on systolic blood pressure. Obstet Gynecol 2005;105:246-254

[17] Neilson J. Pre-eclampsia and eclampsia. In: Lewis G and CEMACH. Why Mothers Die 2003-2005. London: RCOG Press, 2007 : 72.

Table 1. Events in dead mothers $(n=25)$

\begin{tabular}{|c|c|c|c|}
\hline Serial no & Events of dead mothers & & Number (\%) \\
\hline \multirow[t]{3}{*}{1} & \multirow{3}{*}{$\begin{array}{l}\text { Mode of delivery } \\
\text { (antepartum eclampsia=21) }\end{array}$} & Vaginal & $11(52.38 \%)$ \\
\hline & & Caesarean & $1(4.7 \%)$ \\
\hline & & Undelivered & $9(42.85 \%)$ \\
\hline \multirow[t]{2}{*}{2} & \multirow[t]{2}{*}{ Number of convulsion } & $\leq 5$ & $14(56 \%)$ \\
\hline & & $>5$ & $11(44 \%)$ \\
\hline \multirow[t]{2}{*}{3} & \multirow{2}{*}{$\begin{array}{l}\text { Admission Delivery interval (hours) } \\
(\mathrm{n}=21)\end{array}$} & $\leq 12$ & $7(33.33 \%)$ \\
\hline & & $>12$ & $2(9.52 \%)$ \\
\hline \multirow[t]{2}{*}{4} & \multirow[t]{2}{*}{ Neonatal outcome $(\mathrm{n}=21)$, 3pair twins } & Live born & $10(47.61 \%)$ \\
\hline & & Still born & $14(66.66 \%)$ \\
\hline \multirow[t]{2}{*}{5} & \multirow[t]{2}{*}{ Admission- Death interval (hours) } & $<12$ & $9(36 \%)$ \\
\hline & & $\geq 12$ & $16(64 \%)$ \\
\hline
\end{tabular}


Table: 2 showing cause of death of the eclampsia mothers $(n=25)$

\begin{tabular}{|l|l|l|l|}
\hline Serial no. & Cause of death & No. of mothers & Percentage $(\boldsymbol{\%})$ \\
\hline $\mathbf{1}$ & Cerebral hemorrhage & 10 & 40 \\
\hline $\mathbf{2}$ & Pulmonary edema & 7 & 28 \\
\hline $\mathbf{3}$ & Postpartum hemorrhage & 3 & 12 \\
\hline $\mathbf{4}$ & Hepatic coma & 2 & 08 \\
\hline $\mathbf{5}$ & Aspiration & 1 & 04 \\
\hline $\mathbf{6}$ & Septicemia & 1 & 04 \\
\hline $\mathbf{7}$ & Acute renal failure & 1 & 04 \\
\hline Total & & 25 & 100 \\
\hline
\end{tabular}

